\title{
MDM2-dependent inhibition of P53 is required for Epstein-Barr virus $B$ cell growth transformation and infected cell survival E Forte and MA Luftig*
}

Address: Department of Molecular Genetics and Microbiology, Duke University Medical Center, Durham, North Carolina, USA

* Corresponding author

\author{
from I I th International Conference on Malignancies in AIDS and Other Acquired Immunodeficiencies (ICMAOI): Basic, Epidemiologic, and Clinical \\ Research \\ Bethesda, MD, USA. 6-7 October 2008 \\ Published: 17 June 2009 \\ Infectious Agents and Cancer 2009, 4(Suppl 2):P26 doi:10.1 186/1750-9378-4-S2-P26
}

This abstract is available from: http://www.infectagentscancer.com/content/4/S2/P26

(C) 2009 Forte and Luftig; licensee BioMed Central Ltd.

Epstein-Barr virus (EBV) growth transformation of primary B lymphocytes into indefinitely proliferating lymphoblastoid cell lines (LCLs) depends on the concerted activities of a subset of viral proteins expressed during latency. EBV drives quiescent B cells into S phase and consequently a host response is activated that includes expression of p53 and its target genes. Since LCLs retain wildtype p53, it was of interest to determine what contribution the p53 pathway may have in controlling established LCL growth and EBV-mediated transformation of primary B cells.

We found that liberation of p53 through chemical antagonism of one of its major ubiquitin ligases, MDM2, led to apoptosis of established LCLs and suppressed EBV-mediated transformation of primary B cells. The activation of latent p53 induced target genes associated with apoptosis and was antagonized by constitutive NFkB activity in LCLs. Furthermore, the NFKB-dependent antagonism of p53 was not at the p53-dependent transcriptional level, but rather involved increasing the level of steady-state MDM2 protein. The consequence of these effects through $\mathrm{NF \kappa B}$ is to increase the MDM2/p53 ratio, thereby sensitizing cells to MDM2 antagonism. This mechanism, likely through increased MDM2 translation, may provide a novel means by which NFKB activating oncogenes suppress wild-type p53 activity and overcome the oncogenic stress checkpoint. Furthermore, the acquisition of Nutlinsensitivity in EBV-infected cells provides a novel system for studying the pathways that dictate LCL survival and regulate EBV transformation. Finally, MDM2 antagonists may be considered alone or in combination with NFkB inhibition for therapeutic intervention in EBV-associated malignancies expressing wild-type $\mathrm{p} 53$. 